\title{
Los cambios en la estructura tributaria de El Salvador: Implicaciones • para el desarrollo
}

\author{
Dr. J. Michael McGuire \\ Profesor Visitante Depto. de Economia
}

\section{Introduccion}

En su recién encíclica Sollicitudo Rei Socialis, el Papa Juan Pablo II enfatiza repetidas veces que "una de las mayores injusticias del mundo contemporáneo consiste precisamente en esto: en que son relativamente pocos los que poseen mucho, y muchos los que no poseen casi nada. Es la injusticia de la mala distribución de los bienes y sevicios destinados originariamente a todos"'.

Una de las causas más importantes de esta mala distribución es que su "derecho a participar en la construcción de la sociedad... o tomar iniciativas en materia económica está negado o limitado... Y esto sucede no por responsabilidad de las poblaciones indigentes..."

Planteamientos pasados de desarrollo han fracasado precisamente porque no han incorporado a tantas personas necesitadas en el proceso de desarrollo y sus beneficios. Claro, se necesita cambiar. EI Papa Juan Pablo pide una nueva explosión de creatividad para desarrollar una nueva "concepción más rica y diferenciada de desarrollo" que sirve el "desarrollo de toda la persona y de todas las personas"3.

Recientemente, el gobierno nacional de El Salvador comenzó un proceso de largo plazo para cambiar radicalmente el sistema tributario del pais. Este cambio es un medio importante de implementar el plan económico de desarrollo del gobierno. La cuestión es: ¿Representa el cambio un planteamiento nuevo y creativo de desarrollo que promete 
incorporar a las mayorias populares de El Salvador en el proceso de desarrollo tan plenamente como posible?

El propósito de este trabajo es explorar esta cuestión. La parte I describe el sistema tributario de El Salvador, y tanto los cambios realizados como los cambios propuestos en ese sistema. La parte II utiliza la teoría económica del mercado para analizar los efectos económicos de los cambios en términos tanto para estimular el desarrollo, como para incorporar a las mayorías en el proceso de desarrollo. La parte III deriva implicaciones para el proceso de desarrollo y clarifica la naturaleza de algunas cuestiones que tal vez el pueblo salvadoreno quisiera considerar para determinar la naturaleza de cambios futuros.

\section{LA PARTE I: EL SISTEMA TRIBUTARIO}

\section{La estructura tributarla}

El Apéndice I presenta un resumen auto-explicativo de la estructura tributaria de EI Salvador.` EI ministerio de Hacienda de EI Salvador divide los impuestos en dos grandes categorias, "Impuestos Directos" e "Impuestos Indirectos". Aunque esta distinción es poco ambigua, se define los "Impuestos Directos" como los impuestos pagados inicialmente por las personas que sufre el gravamen del impuesto. Los "Impuestos Indirectos" son impuestos que se trasladan de la persona legalmente responsable para pagar el impuesto a otras personas. Bajo cada impuesto se encuentra una definición del impuesto.

Los porcentajes entre paréntesis dan el porcentaje del ingreso tributario total que cada impuesto dio en el ano 1989. Se ve que en 1989, Impuestos Directos representaron el $30.9 \%$ de todos los ingresos tributarios, mientras que los Impuestos Indirectos representaron el $69.1 \%$. EI Impuesto Directo más importante en términos de ingreso es el Impuesto Sobre la Renta (23.7\%). Los Impuestos Indirectos más importantes son los Impuestos al Comercio Exterior (18.1\%), los Impuestos al Consumo de Productos (17.5\%), y el Impuesto de Timbres (31.1\%).

\section{Los camblos reallzados y los camblos propuestos}

El Apéndice II da un resumen de los cambios realizados y propuestos del sistema tributario de El Salvador. El apéndice hace claro el punto importantísimo que los cambios de enero de 1990 (los cambios realizados) son nada más que un comienzo, y que el gobierno ha entrado en un proceso de largo plazo y que tiene la intención de rees- 
tructurar el sistema tributario muy profundamente, para hacer más "cambios propuestos" en el futuro. El Ministro de Hacienda, el Lic. Alvarado Cano hizo bien claro este punto importante cuando escribio "Es importante saber también hacia donde nos dirigimos... Lo principal es que estamos implementando un proceso. En este sentido son los objetivos los que deben constituir la preocupación de los sectores productivos y del público en general. Por tanto lo más importante es la senal de mediano y largo plazon.5

La descripción de los cambios realizados son derivados principalmente de dos fuentes: 1) un folleto distribuido durante una presentación pública por el Sr. Ministro de Hacienda, el Lic. Alvarado Cano de los cambios tributarios; 2 ) un análisis descriptivo conducido por la firma Peat Marwick de San Salvador. La descripción de los cambios propuestos es derivada de un documento elaborado por el Ministerio de Hacienda y de dos entrevistas con el Lic. Rogelio Tovar, el Director de Impuestos Internos. ${ }^{\circ}$

Los "cambios realizados" del Apéndice II son cambios que se hicieron ley el 1 de enero de 1990. Los "cambios propuestos" son cambios que el gobiemo ha declarado que quiere hacer en el futuro. El apéndice no presenta todos los cambios del sistema tributario, sino los cambios que le parecen al autor ser los cambios más importantes en términos de influenciar la capacidad de las mayorias populares a incorporarse en el proceso de desarrollo. Claro, los cambios propuestos tendrán el papel más importante es incorporar o en excluir a las mayorias del proceso de desarrollo.

La característica más importante de los cambios es que los Impuestos Directos son reducidos bastante, pero, excepto por los cambios de los impuestos al comercio exterior, se ve muy poco cambio de impuestos indirectos. El plan de largo plazo es reducir la tasa marginal máxima del Impuesto Sobre la Renta de Personas de 60\% a $20-25 \%$. Se quiere reducir la tasa marginal máxima del Impuesto Sobre la Renta de las Empresas de $35 \%$ a $20-25 \%$ y se quiere eliminar los tramos (o la progresividad) de este impuesto. A largo plazo, se quiere eliminar completamente el Impuesto al Patrimonio. El cambio más grande entre los impuestos indirectos son un programa gradual y comprensivo de desgravación arancelaria. Más allá de eso, el único cambio de tasas que interesa es el incorporar a tributar el $5 \%$ de Timbres a varias ventas que antes pagaban menos de $5 \%$. También, un esfuerzo para reducir la evasión de Timbres está en progreso. Un paso importante para reducir la evasión de impuestos sobre la venta será el convertir el Impuesto Timbres al Impuesto IVA en 1992. La cuestión es: ¿Cuál será 
el efecto de estos cambios sobre el desarrollo del país y cormo sinen para incorporar a las mayorías populares en este proceso de desarrollo?

\section{LA PARTE II: ANALISIS DE CAMBIOS}

\section{La metodologla}

El propósito de esta sección es analizar los efectos económicos de los "cambios propuestos" de la estructura tributaria. Se da énlasis a analizar la capacidad de los cambios a incorporar a los miembros más necesitados del país en el proceso de desarrollo. El enfoque consiste en identificar los "efectos primarios", o las respuestas de los compradores y vendedores en el mercado en que se pone el impuesto porque estas respuestas normalmente son decisivas en determinar los efectos económicos de impuesto. Las repercusiones secundarlas en otros mercados de productos y factores de producción serán consideradas en donde parece que estos efectos tienen un Impacto importante en el desarrollo.

Varios aspectos de cada impuesto que se dirigen directamente a incorporar a las mayorías en el proceso de desarrollo serán considerados. La incidencia tributaria, o el pagador final del Impuesto después de cualquier traslación, será considerada para identificar el efecto del impuesto sobre la distribución de ingreso. Esto determina la equidad del impuesto, pero lo más importante para nuestro propósito es el hecho que el ingreso disponible es un determinante importante de la capacidad de una persona a participar en el proceso de desarrollo. Los efectos sobre la producción serán considerados porque esto determina el nivel de empleo, una forma de participar en el desarrollo; se puede aumentar la producción aumentando la demanda o aumentando los ahorros y la inversión. Los efectos sobre ingreso tributario serán considerados porque esto determina la capacidad del gobiemo para suministrar los bienes y servicios básicos como la educación que, en si, determinan la capacidad de las mayorlas para participar en el proceso de producción; los efectos sobre el ingreso tributario también pueden causar cambios adicionales en el sistema de impuestos que afectan a las mayorias populares. 


\section{El IMPUESTO SOBRE LA RENTA DE PERSONAS}

\section{La Incidoncla}

Normalmente, se asume que el Impuesto Sobre la Renta de Personas es pagado por la persona que gana la renta. Se supone que las ofertas de tierra, trabajo, y capital son perfectamente inelásticas (verticales), por lo menos en el corto plazo. Se asume que la oferta de tierra es inelástica porque la cantidad de tierra disponible es fija. Se asume que las ofertas de trabajo y capital son perfectamente inelásticas porque el impuesto es general, y por lo tanto no se puede evadir el impuesto por mudarse.?

El gráfico 1 ilustra el mercado de cualquiera de los tres factores de producción. La inelasticidad de oferta está ilustrado por la línea vertical, 0 . El efecto del impuesto es causar que la demanda del factor caiga verticalmente de $D_{1}$ a $D_{2}$ por la cantidad del impuesto sobre cada factor. La demanda más baja, $D_{2}$, representa el precio neto que los empleadores están dispuestos a pagar por el factor de producción después del impuesto; la demanda superior, $D_{1}$, representa el precio bruto que están dispuestos a pagar. Se ve que ni la cantidad del factor ni el precio bruto cambia como respuesta al impuesto; pero el precio neto pagado al factor cae por 2 colones, el monto del impuesto sobre cada unidad del factor. Una reducción del impuesto tiene el efecto opuesto: las ganancias de cada factor gravado se aumentan por el monto de la reducción del impuesto. La reducción del impuesto beneficia al ganador de la renta.

Gráflco 1

Impuesto Sobre la Renta Personal

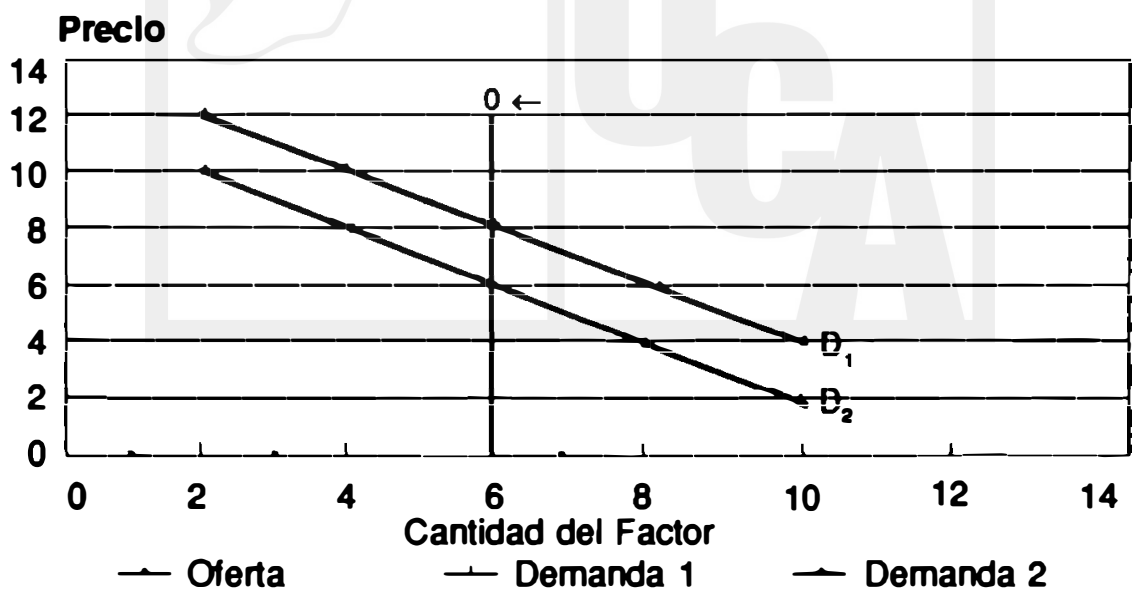




\section{Lo equidad vertical}

Un impuesto es progresivo si las personas con ingresos más altos pagan un porcentaje más alto de su ingreso cormo impuesto que las personas de ingresos menores. El impuesto sobre la renta de las personas es progresivo porque el ganador paga el impuesto, porque las tasas marginales aumentan con ingreso, y porque la posesión de tierra y de capital es altamente concentrada entre personas con ingesos más altos.

El gráfico 2 ilustra como las tasas "efectivas" del impuesto son cambiadas por la reforma "realizada" y la reforma "propuesta". Las tasas son "efectivas" en el sentido limitado que son el porcentaje de la renta imponible que será pagado al gobiemo en forma de un impuesto. Una lista de las tasas propuestas no ha sido por el gobiemo publicado; por eso, la curva del gráfico es dibujada asumiendo que todas las tasas son reducidas por la reducción de $60 \%$ de la tasa máxima (de $60 \%$ a $20 \%$ ), y que los descuentos son el mismo porcentaje del impuesto inicial que los descuentos de los cambios realizados."

\section{Gráflco 2}

Tasa Efectiva de Impuesto Sobre la Renta

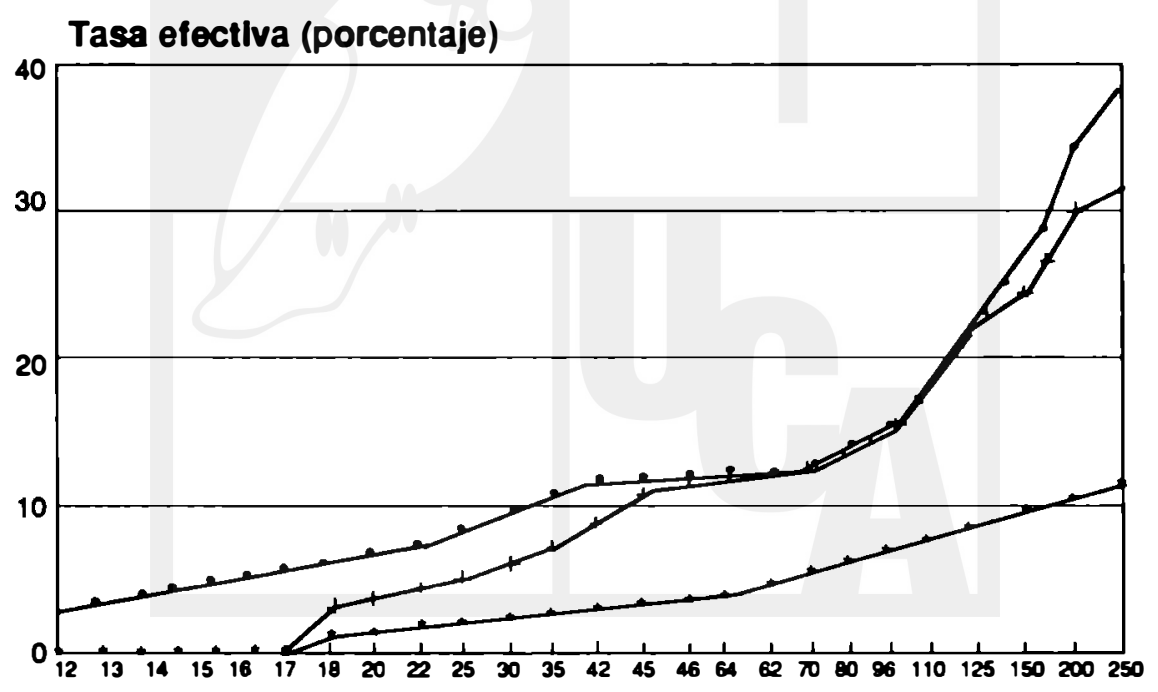

Renta Imponlble (mlles de colones)

- Tasa anterlor 1 Tasa reallzada

- Tasa propuesta 
El gráfico demuestra una reducción grande en las tasas ofectivas: la tasa más baja cae de $5.6 \%$ a $1.1 \%$, mientras que la tasa efectiva por la renta imponible de 250,000 colones cae de $36.9 \%$ a $12.6 \%$. El gráfico también muestra una reducción grande en la progresivldad del impuesto en que habrá una diferencia mucho más pequena entre la tasa máxima y la tasa mínima: tasas efectivas antes del cambio de 1990 variaban de $3.6 \%$ a $36.9 \%$; las tasas propuestas varlan de $1.1 \%$ a $12.6 \%$. Claro, el plan del gobierno es construir un sistema tributario en que el impuesto sobre la renta personal toma un papel mucho más pequeno que su papel anterior.

Este papel reducido del impuesto sobre la renta es una sorpresa en parte porque tradicionalmente el impuesto sobre la renta ha sido considerado el mejor de todos los impuestos. Se piensa que el impuesto es justo porque la renta, definida anchamente como el acrecentamiento total a la riqueza de una persona, es la mejor medida de capacidad de pagar. Fácilmente se puede ajustar el impuesto para tomar en cuenta las circunstancias personales del pagador: tasas progresivas ponen un impuesto más alto sobre ellos que tienen más capacidad de pagar; se puede utilizar exenciones y deducciones para proveer la renta básica que se necesita para sobrevivir y para compensar los costos de ganar la renta. El impuesto sirve bien al gobierno en cumplir su papel de redistribuir del ingreso. El impuesto distorsiona muy poco las decisiones económicas, y puede ser una fuente importante de ingreso que crece con la economia. Se puede administrarlo fácilmente después de establecer las condiciones básicas de implementar el impuesto. Por todas estas razones la recomendación normal para los países en vias de desarrollo es aprender de la experiencia y expandir el uso del impuesto sobre la renta en cuanto son posible ${ }^{9}$. ¿Cuál es la razón fundamental del gobierno para hacer este cambio sorpresivo? ¿Es probable que las metas del gobierno serán logradas?

\section{Los ahorros y la Inversión}

Es cierto que una justificación más importante a favor de la reforma del impuesto sobre la renta de personas es que las reducciones, especialmente las reducciones de los impuestos sobre los más ricos, ofrecen esperanza de generar ahorros que, se supone, pueden servir para aumentar la inversión y el desarrollo. El Ministro de Hacienda dio esta justificación cuando escribio: "Esto implica que aumentará su capacidad de consumo y su capacidad de ahorro.... al ahorrar más están permitiendo un mayor volumen de inversión, lo cual significa que habrá más producción, empleo e ingresos y por tanto mayor recaudación tributaria." ${ }^{10}$ Para evaluar esta justificación, tenemos que pre- 
guntamos si es probable que al reducir los impuestos sobre la renta de las personas vayan a aumentar los ahorros y la inversión.

\section{Las proposiclones de los ahorros}

La justiticación para reducir la progresividad del impuesto sobre la renta de las personas viene de la idea que los ahorros como una proporción de la renta, aumentan con la renta. Estudios empirioos de presupuestos confirman que la proporción de ingreso ahorrado sl aumenta con el nivel de ingreso." Por lo tanto se concluye que la mejor manera de estimular los ahorros es reducir los impuestos sobre las personas más ricas.

Hay por lo menos tres debilidades en este argumento. La primera es que la variable relevante no es la tasa promedio, sino la tasa marginal de los ahorros. La proporción de un aumento de renta disponible que será ahorrada es determinada por la tasa marginal, no la tasa promedio, de ahorrar. Un aumento de tasas promedios de ahorro no es inconsistente con una tasa marginal constante. En términos gráficos, una línea recta de ahorros que corta el eje horizontal de ingreso a un nivel de ingreso mayor que cero demuestra una tasa marginal constante, y una tasa promedio creciente, de los ahorros. En este caso, ahorros son aumentados (o desahorros son reducidos) igualmente por cambios marginales de los ingresos (disponibles de los ricos o de las mayorlas. Musgrave concluye que "...aunque las propensiones promedios de ahorrar difieren mucho, las respectivas propensiones marginales difieren mucho menos... Basado en las diferencias entre las propensiones a ahorrar, es improbable que cambios factibles de la estructura tributarias vayan a tener un efecto grande en la tasa de ahorro de la economia." ${ }^{12}$

Otra dificultad con este argumento es que los estudios de presupuestos familiares exageran las diferencias en tasas promedios de ahorro porque tratan un solo ano, y porque el consumo familiar es más estable que el ingreso. En cualquier ano, las clases ricas incluyen familias con ingresos temporalmente attos quienes mantienen sus niveles bajos de consumo y por lo tanto generan tasas altas de ahorros. Similarmente, en cualquier ano, las familias con ingresos temporalmente reducidos se encuentran entre las clases económicas bajas. Estas familias mantienen sus niveles altos de consumo y así generan tasas bajas de ahorro. El resultado es que las proporciones de ahorro de las familias con los ingresos altos parecen más altas que en realidad son, y las proporciones de ahorros de las familias con los ingresos bajos parecen más bajas que en realidad son. 


\section{El Efecto-Ingreso vs. El Efecto-Sustltuclón}

Un argumento segundo a favor de reducir el impuesto sobre la renta de las personas es que la reducción aumenta el beneficio de ahorrar porque se paga menos impuestos sobre la renta que viene en forma del interés. Este aumento de beneficio da un incentivo de ahorrar más en vez de consumir. La reducción del impuesto causa to que se llama un "Efecto-Sustitución" del consumo por los ahorros.

La debilidad de este argumento viene del hecho de que el aumento del beneficio de ahorrar también reduce la cantidad de los ahorros necesaria para hacer una compra futura o para proveer un ingreso para el retiro. Este "Efecto-Ingreso" opera en la dirección opuesta y tiende a reducir los ahorros.

Asl, la reducción de un impuesto sobre la renta de las personas crea tanto un "Efecto-Sustitución" que aumenta los ahorros como un "Efecto-Ingreso" que los disminuye. No se sabe teóricamente cual efecto domina. Tampoco no ha sido posible determinar por investigaciones empíricas cual efecto domina. ${ }^{13}$ Claro, el "Efecto-Ingreso" tiende a anular el "Efecto-Sustitución", y, por lo tanto es posible que reducir el impuesto sobre la renta de las personas no tenga absolutamente ningún efecto positivo sobre los ahorros y la inversión.

\section{La experlencla de los Estados Unldos}

Un argumento tercero que levanta dudas sobre a política de reducir el impuesto sobre la renta de las personas para estimular los ahorros y la inversión es la experiencia de los Estados Unidos con un experimento similar conducido durante la década 1980-1990. Los impuestos estadounidenses sobre la renta fueron reducidos fuertemente en el ano 1981 y otra vez en 1986, pero estas reducciones no tuvieron ningún efecto positivo sobre los ahorros. Al contrario, los ahorros personales como porcentaje de la renta disponible variaban entre el 7 y el 8 porciento de 1960 a 1980, pero cayeron a una cifra menor que el 4 porciento al fin de la década de los $1980 .{ }^{14}$ El profesor Joseph Pechman, uno de los más respetados economistas tributarios de los Estados Unidos concluye de un examen tanto de los estudios empiricos como de la experiencia de los Estados Unidos que "la conclusión más fuerte que uno puede hacer de la evidencia disponible es que los efectos de los impuestos sobre los incentivos han sido relativamente pequenos... si las tasas triburarias no son elevadas a niveles punitivos, las consideraciones de los incentivos no justifican un descuido del objetivo distribucional de la política tributaria." 15 
¿Qué significa esto para las mayorias populares ? Primero, implica que nuevos empleos no serán generados por un aumento del ahorro y de la inversión. Segundo, implica que los ingresos tributarios del gobierno van a tender a caer, creando asi un déficit. Como resultado, se puede esperar un aumento de otros impuestos, posiblemente de los impuestos regresivos, para compensar. Alternativamente, una reducción de los servicios públicos como la educación que aumentan la capacidad de las mayorias para participar en el proceso de desarrollo puede tomar lugar. Es instructivo notar que las reducciones estadounidenses de los impuestos sobre la renta han terminado en un aumento del déficit del pais de $\$ 60$ billones de dólares en 1980 a un déficit estimado de $\$ 300$ billones en 1991. Recientemente, el Presidente Bush comenzó a atacar este déficit por aumentar los impuestos regresivos sobre las bebidas alcohólicas.

\section{Otras consideraclones}

Aumentar los ahorros y la inversión no es la única razón que tiene el gobierno a favor de reducir el impuesto sobre la renta. Otra defensa de la política es reducir la evasión. El plan es aumentar el número de pagadores de impuestos por reducir el incentivo a evadir el impuesto, $y$, a la vez, mejorar la administración del impuesto por aumentar el control y hacer más fuertes las sanciones. Asi se espera evitar una pérdida de ingresos tributarios aunque si la reducción de tasas marginales no aumente los ahorros y la inversión.

El supuesto que el aumento del cumplimiento voluntario va a ser suficiente para evitar pérdidas del ingreso tributario parece cuestionable. Se planea mejorar la administración de este impuesto solamente en el futuro distante después de mejorar la administración del impuesto al Timbre. ${ }^{16}$ También, este argumento tiene el supuesto implicito que solo un mejoramiento de administración, incluyendo el mejor control y las sanciones más fuertes, no basta para reducir la evasión a niveles aceptables. ¿No seria mejor tener las tasas más progresivas con una administración mejorada? El pueblo salvadoreno tendrá que decidir si el "mundo real" es tal que es necesario sacrificar la "equidad vertical" entre las clases económicas, dada por las tasas progresivas para lograr la "equidad horizontal" que viene de todos los miembros de cada clase pagando sus impuestos legalmente debidos.

Otra defensa del gobierno a favor de su política es que el poner más dinero en manos privados va a estimular la demanda ("consumo") y la producción. Esto si pasó en los Estados Unidos. De veras, el pals ha disfrutado un periodo largo de prosperidad durante la década de los 
anos 1980. Sin embargo, como ya se mencionó, la prosperidad no bastó para evitar el déficit más grande de la historia del país y un comienzo de un aumento de impuestos regresivos para reducirlo. La evidencia preliminar es que una economia no puede soportar una desgravación radical como la planeada por el gobierno de El Salvador sin estimular bastante los ahorros y la inversión. Al mismo tiempo parece bien dudoso que una desgravación radical del impuesto sobre la renta de las personas puede producir ese estimulo necesario. Sin este estimulo, la prosperidad es una "prosperidad prestada" $y$, pronto 0 tarde, se tiene que pagar la cuenta.

\section{EL IMPUESTO SOBRE LA RENTA DE EMPRESAS}

\section{La Incidencla}

Aunque los empresarios de vez en cuando arguyen que trasladen sus impuestos sobre la renta hacia sus consumidores al aumentar sus precios, el argumento teórico es que no se puede trasladar el impuesto hacia los consumidores, y que el impuesto es pagado principalmente por los empresarios. La razón es que el precio y la cantidad que maximizan utilidades no se cambian por un impuesto sobre la renta de las empresas. Si una empresa cobra el precio que maximiza las utilidades antes del impuesto, no sirve aumentar el precio, reducir utilidades, y pagar un impuesto sobre utilidades reducidas. La misma conclusión surge, aunque la empresa sea un monopolio"7.

Es especialmente dificil para los empresarios de paises pequenos que son fuertemente dependientes del comercio internacional trasladar un impuesto hacia los consumidores. Para estos paises, los precios de exportaciones son fijados en mercados internacionales, y no existe casi ninguna posibilidad de trasladar un impuesto sobre utilidades hacia consumidores extranjeros. En el caso de bienes producidos para consumidores locales, no hay casi ninguna posibilidad de trasladar adelante el impuesto si parte del mercado es suministrado por importaciones. Los estudios empíricos no ayudan mucho a determinar si los impuestos sobre la renta de las empresas son trasladados adelante, por dificultades estadisticas al medir las variables relevantes y al aislar su influencia ${ }^{19}$. Esto hace el impuesto sobre la renta de las empresas progresivo porque los duenos son generalmente personas de las clases económicas altas.

Aunque sea dudoso que el impuesto sobre la renta de las empresas es trasladado adelante a los consumidores, es posible que parte del 
impuesto sea trasladado para atrás a los trabajadores en EI Salvador. Donde el trabajo está relativamente débil y los empleadores relativamente fuertes (condiciones que aparentemente existen en El Salvador), los sueldos pueden ser reducidos como una respuesta a impuesto.

\section{Los ahorros y la inversión}

El efecto inmediato de rebajar el impuesto sobre la renta de las empresas es aumentar la utilidad neta que queda después de los impuestos y que los empresarios pueden utilizar para aumentar los ahorros y la inversión. Estudios empiricos conducidos en los Estados Unidos sugieren que en el largo plazo, una reducción del impuesto sobre la renta de las empresas puede aumentar los ahorros de la empresa en un $50 \%$ de la reducción ${ }^{19}$. Asi, el impacto sobre los ahorros de reducir el impuesto sobre la renta de empresas es batante más grande del impacto de reducir la mayoria de otros impuestos.

Los ahorros son una condición necesaria para la formación de capital, pero no son una condición suficiente. También es necesario que los empresarios estén dispuestos a invertir algo que posiblemente no estén dispuestos a hacer en el ambiente conflictivo, incierto, y deprimido de EI Salvador. Por lo tanto, la reducción de impuestos sobre la renta de las empresas puede aumentar los ahorros considerablemente más que la inversión. El efecto sobre el empleo de las mayorias dependerá en si las empresas invierten sus ahorros.

Investigaciones recientes han renovado el interés en promover la micro y pequeña empresa como instrumento de desarrollo. El Profesor David Birch de la universidad Massachusetts Institute of Technology (MIT) condujo un estudio monumental de 5.6 millones de empresas de los Estados Unidos, y concluyó que las empresas pequenas, jóvenes, e independientes generaron la mayoria de empleos nuevos en los Estados Unidos entre los anos 1960 y $1976^{20}$. El autor arguye que el potencial de empresas pequenas ha sido fuertemente subestimado, y que la política gubernamental debe ser reorientada en lugar de un énfasis demasiado grande en promover empresas grandes, y hacia un mayor énfasis en promover la empresa pequena. Esto podria ser un medio importante de incorporar a las mayorias en el proceso de desarrollo.

Se puede usar la progresividad del impuesto sobre la renta de empresas para dar auxilio tributario y una ventaja relativa a empresas pequenas, y para superar algunas de las bien conocidas desventajas que oprimen esos negocios. La reforma tributaria propuesta elimina la progresividad del impuesto sobre la renta de empresas. El Ministro de 
Hacienda justificó esta eliminación diciendo: "eliminaremos ese esquema de distintos tramos, por que no es cierto que este tipo de escalonamientos beneficie a la pequena y micro empresa... La mayoría de las empresas que están en los tramos bajos son subsidiarias sucursales o partes de holdings de empresas más grandes".21 Una cuestión de política puede ser el uso de la progresividad con provisiones especiales por sucursales para promover la pequena empresa sin desperdiciar ingresos. Tal vez se pueda prómover tanto los ahorros como a la empresa pequena al reducir el impuesto, pero a la vez mantener su progresividad.

\section{LOS IMPUESTOS SOBRE EL PATRIMONIO DE PERSONAS $Y$ DE EMPRESAS}

\section{La Incldencla}

Un impuesto nacional uniforme sobre el valor de todo el patrimonio (tierra y bienes de capital) es pagado principalmente por los duenos del patrimonio.22/Los duenos no pueden evitar el impuesto nacional porque no puede mudar sus activos a sectores que no son gravados, y no pueden elevar sus precios. La primera avenida de escape está cerrada porque todos los sectores son gravados igualmente. La segunda está cerrada porque, si los duehos minimizan sus ingresos, el precio en que se maximiza las utilidades no se cambia debido a un impuesto nacional sobre el valor de activos. Esta conclusión sigue de la uniformidad de la tasa del impuesto en todos los sectores y del supuesto que las ofertas agregadas de tierra y capital son fijas.

El impuesto nacional de El Salvador sobre el patrimonio es un impuesto progresivo tanto porque la posesión de patrimonio sube rápidamente con el ingreso, y porque las tasas marginales del impuesto del pals son progresivas. Es posible que esta progresividad sea reducida en parte, si se traslada el impuesto sobre el patrimonio de las empresas para atrás hacia los trabajadores, suponiendo que el trabajo es principalmente no capacitado y si gana sueldos bajos. Como un impuesto progresivo, el impuesto sobre el patrimonio puede servir como una fuente equitativa de fondos para satisfacer las necesidades básicas de las mayorias, y para prepararlas a incorporarse en el proceso de desarrollo.

\section{Los ahorros y la Inversión}

La creencia que se pueden aumentar los ahorros y la inversión al 
reducir el impuesto sobre el patrimonio, viene de la creencia que una reducción del impuesto aumenta la tasa de ingreso para los duenos del patrimonio, y que esto tiene el efecto de largo plazo de motivarlos a aumentar los ahorros y la inversión. ¿En qué medida es probable que esto pasará?

Un impuesto nacional sobre todo el patrimonio es equivalente a un impuesto sobre el ingreso de capital. En un mecado en donde el capital da una tasa de retorno del $10 \%$, la incidencia de un impuesto general sobre el valor del patrimonio gravado a una tasa de 5 colones por 100 colones de valor es equivalente a un impuesto de $50 \%$ sobre la renta de capital. ${ }^{23}$ Por esto un impuesto nacional sobre el patrimonio tiene el mismo efecto sobre los ahorros y la inversión que un impuesto personal sobre la renta de capital, y que todo to que fue dicho antes sobre el impuesto sobre la renta de capital se aplica al impuesto sobre el patrimonio: el análisis teórico no da ninguna indicación si estos efectos son grandes o pequenos, y el análisis empirico no es concluyente.

Aaron concluye su análisis del efecto del impuesto sobre los ahorros y la inversión usando el mismo tono que usaron Musgrave, Goode, y Pechman al hacer sus conclusiones sobre la eficacia del impuesto personal sobre la renta: "Algunos economistas han detectado un pequeno efecto positivo de la tasa de retorno sobre los ahorros; otros han detectado efectos negativos; algunos han identificado sesgos en la mayoria de los intentos de medición que los hacen esencialmente inútiles. Otros economistas han notado la casi sobrenatural constancia de ahorros sobre muchas décadas, cuando han ocurrido cambios masivos de impuestos, de ingreso, y de casi todos los otros factores que supuestamente determinan los ahorros. El fracaso de detectar un impacto de toda la política tributaria sobre la tasa de ahorros hace bien dificil asignar una influencia sigificativa del impuesto sobre el patrimonio a la acumulación de capital". ${ }^{24}$ Por tanto, parece bien improbable que 0 en el corto plazo o en el largo plazo la eliminación del impuesto sobre el patrimonio tendrá un efecto significativo sobre los ahorros y la inversión". La implicación es que no habrá un aumento de empleos para las mayorias creado por los ahorros y la inversión.

Hay razón para creer que en algunos casos se puede estimular el desarrollo, no por eliminar el impuesto sobre el patrimonio, sino por mantenerlo o aun aumentarlo. Se puede utilizar un impuesto sobre la renta, especialmente sobre la tierra de paises en vias de' desarrollo, para estimular un uso más efectivo de la tierra agricola y para disgregar tenencias grandes. Si un terrateniente tiene que pagar un impuesto sobre el valor de su tierra, recibe de eso un incentivo para usar 
la tierra más intensivamente para ganar ingresos que se pueden utilizar para pagar el impuesto. Si el dueño no quiere usar la tierra, el impuesto lo motiva a vender la tierra en vez de sufrir la pérdida de pagar el impuesto. El impuesto más apropiado para lograr esta meta es un impuesto progresivo sobre la tierra que discrimina en contra de tierras ociosas o subutilizadas.

\section{Otras consideraclones}

El impuesto sobre patrimonio es una medida suplementaria de la capacidad de pagar, especialmente en una sociedad agricola. Claro, una persona con un ingreso de 100,000 colones y patrimonio de $1,000,000$ colones tiene más capacidad para pagar impuestos que la persona con 100,000 colones y ningún patrimonio. El patrimonio no es un rival del ingreso como la medida primaria de la capacidad para pagar los impuestos. Las consideraciones que apoyan tasas progresivas del impuesto sobre la renta personal también tienen validez con respecto al impuesto sobre el patrimonio. De veras, se puede justificar tasas aun más progresivas porque la posesión y la renta del patrimonio con frecuencia no vienen de esfuerzos personales. El impuesto sobre el patrimonio puede hacer una contribución especialmente poderosa para lograr el objetivo de reducir la desigualdad económica, porque el patrimonio es mucho más concentrado que el ingreso. Este impuesto también es factible en El Salvador ${ }^{25}$. Claro, consideraciones de equidad y administración dan razones fuertes a favor de usar este impuesto para levantar fondos tributarios y para proveer servicios básicos a las mayorias.

\section{EL COMERCIO EXTERIOR:}

\section{EL IMPUESTO SOBRE LAS EXPORTACIONES}

El Apéndice I muestra que casi todos los ingresos tributarios de exportación han venido de la exportación de tres productos agrícolas: el café, el camarón y el azúcar. El cambio realizado elimina el impuesto sobre la exportación del camarón y del azúcar. El cambio propuesto elimina el impuesto sobre la exportación de café. Asi, el plan es eliminar casi todos los impuestos sobre la exportación.

\section{La Incidencla}

Se puede asumir que generalmente la demanda extranjera por los bienes de cualquier pais en via de desarrollo es casi perfectamente elástica (horizontal) porque compradores extranjeros pueden comprar de otros paises; la demanda horizontal indica que el pais exportador 
tiene que aceptar el precio mundial. El gráfico 3 muestra que si la demanda es perfectamente elástica, cualquier impuesto sobre exportaciones será pagado por los productores del país exportador. Antes del impuesto sobre las exportaciones, los productores salvadorenos producen 6 millones de unidades y las venden al precio mundial de 6 colones. El efecto de un impuesto es levantar la oferta verticalmente a $0_{2}$. Dado que el precio intemacional queda constante, la cantidad producida cae a 4 millones de unidades, y el precio neto recibido por los productores cae de 6 colones a 4 colones. La eliminación del impuesto causarla un regreso a la posición original por aumentar el precio neto recibido por los productores de 4 a 6 colones y por aumentar la producción de 4 a 6 millones de unidades.

\section{Gráflco 3}

\section{Impuesto sobre las exportaclones}
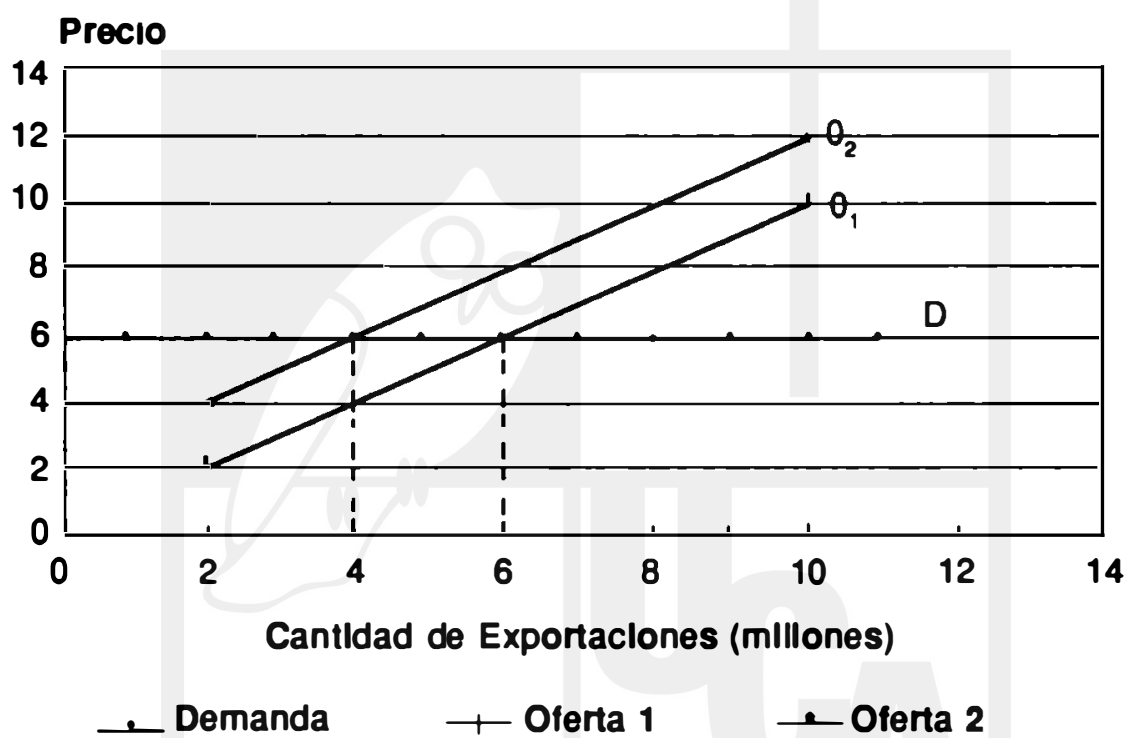

_ Oferta 2

Si el impuesto es progresivo o regresivo ya depende de cuales productores pagan el impuesto. Por cuanto el impuesto cae sobre duenos ricos y trabajadores capacitados, el impuesto es progresivo. Por cuanto el impuesto está trasladado hacia atrás para trabajadores no capa- . citados, la disminución de ganancias es distribuida regresivamente. Los mercados del trabajo son imperfectos, y el uso extensivo de trabajo no capacitado en sectores agrícolas sugieren que una porción sustancial de este impuesto está pagado por los trabajadores no capacitados. 
Estos trabajadores no capacitados están beneficiados por la reducción del impuesto.

\section{La producelón}

Como se espera, estudios estadisticos han encontrado elastlcidades positivas en la producción de café y otros bienes agricolas en Latinoamérica. Esto quiere decir que un aumento del precio neto recibido por productores causa un aumento de producción. cuentra también que diferencias grandes en elasticidades son causadas por variables como estructuras sociales, sistemas de tenencia, tamano de finca, sistemas de mercadeo, etc. Además, las elasticidades no son impresionantemente altas: las elasticidades de corto plazo varlan entre 0.2 y 0.8; las elasticidades de largo plazo son más altas, pero es raro que sean mayor que 1. La implicación de esto es que la eliminación de impuestos sobre la exportación de productos agricolas salvadorenos probablemente vaya a aumentar relativamente poco la producción y el empleo de esos bienes.

Los efectos de la eliminación del impuesto sobre las exportaciones para las mayorias son mixtos. Es posible que trabajadores no capacitados recibirán algunos beneficios en forma de sueldos elevados. Se puede esperar un aumento pequeno de producción y empleo. Por otra parte, el gobierno está perdiendo aproximadamente $5.4 \%$ de sus ingresos tributarios; esto reducirá su capacidad de preparar a las mayorlas a participar más plenamente en el proceso de desarrollo.

Una justificación de este cambio dado por el gobiemo es que se quiere eliminar un sesgo arbitrario en contra de la producción de estos productos. También quieren eliminar una forma de doble tributación sobre los productores de exportaciones. ${ }^{27}$ Una dificultad con esto es que la administración del impuesto sobre la renta es imperfecta, y, como vamos a ver, no hay planes de mejorarla inmediatamente. Entonces será un peligro para la evasión del impuesto.

\section{EL COMERCIO EXTERIOR:}

EL IMPUESTO SOBRE LAS IMPORTACIONES

\section{La Incidencla}

El plan del gobierno es reducir gradual y comprensivamente los impuestos sobre importaciones. En general, se puede asumir que la oferta de bienes importados es casi perfectamente elástica (horizontal) para cualquier pais en via de desarrollo. Esto quiere decir que el precio no depende en la cantidad importada y que los oferentes extranjeros 
venderán sus productos en otros mercados si el pais en via de desarrollo ofrece menos que el precio mundial.

El gráfico 4 indica que si la oferta es perfectamente elástica, un impuesto sobre importaciones es pagado totalmente por los consumidores del pais que importa. Antes del impuesto, $D$ y 0 , determinan que una cantidad de 6 milones de un bien está importada al precio internacional de 6 colones. Se representa un impuesto sobre importaciones por elevar la oferta verticalmente por la cantidad del impuesto sobre cada unidad (de $\mathrm{O}_{1}$ a $\mathrm{O}_{2}$ ). $\mathrm{O}_{2}$ y $\mathrm{D}$ establecen una cantidad nueva de 4 millones de unidades; el precio bruto pagado por consumidores se eleva a 8 colones, mientras que el precio neto recibido por los oferentes queda constante a 6 colones. El impuesto sobre las importaciones está pagado enteramente por los consumidores en la forma de un precio aumentado por 2 colones, el monto del impuesto sobre cada unidad. Esto supone que el impuesto sobre las importaciones pagado por los productores está tratado como un costo de producción y está trasladado hacia el consumidor final. Por todo esto se considera que el impuesto sobre las importaciones es regresivo porque los consumidores pagan el impuesto, y porque el consumo como porcentaje del ingreso cae con un aumento del ingreso. Se concluye que el impuesto sobre las importaciones reduce el ingreso disponible de las mayorias populares; la reducción del impuesto lo aumenta.

Gráflco 4

Impuesto sobre las Importaciones

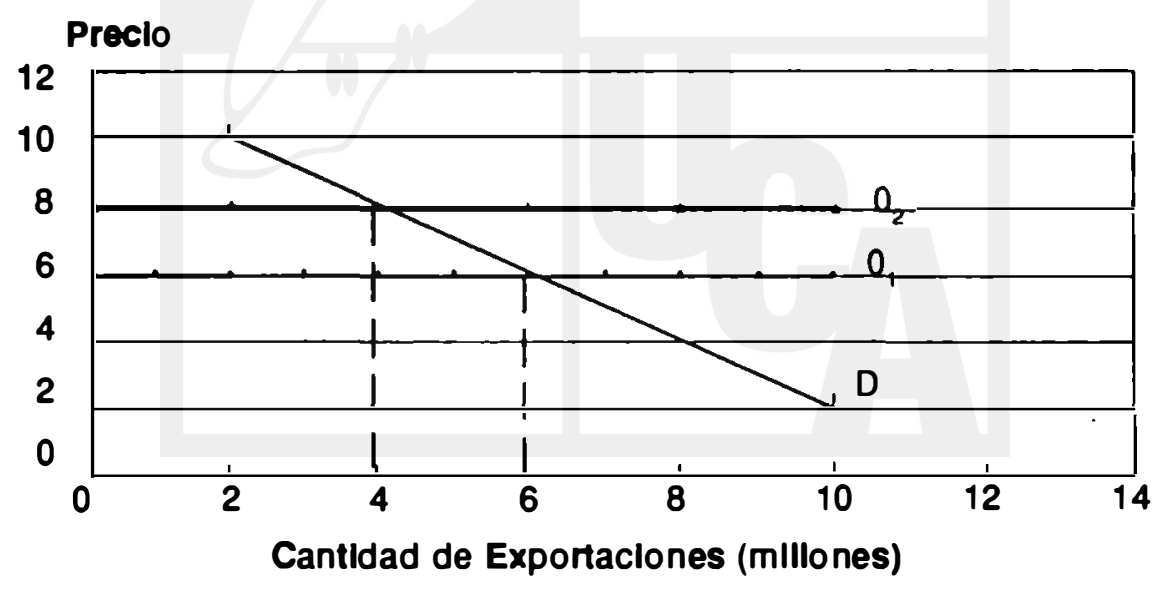

- Oferta 1 - Demanda - Oferta 2 


\section{La produccion}

La reducción del impuesto causa un desplazamiento hacia arriba de la demanda $D_{2}$ hacia la demanda $D_{1}$, una reducción del precio bruto de importaciones y un aumento de la cantidad de importaciones compradas. El ingreso disponible de los consumidores aumenta. La economia es estimulada en que la disminución del precio de importaciones rebaja el costo de producción de los negocios salvadorenos que utilizan importaciones en sus procesos de producción. También, la reducción de los impuestos estimula las exportaciones por dos razones: (1) el costo de importaciones usadas en producir exportaciones cae; (2) la reducción del impuesto aumenta la demanda por divisas para comprar importaciones adicionales; el precio más alto de las divisas que sigue reutuce el precio de las exportaciones salvadorenas.

Una inconveniente es que la protección de las industrias locales es reducida por la desgravación. Por una parte, la reducción de protección puede aumentar la competencia y la eficiencia. Por otra parte, la nueva competencia puede vencer y destruir las empresas relativamente débiles. En estos casos se sufre una disminución del empleo y de los salarios.

\section{EL IMPUESTO AL CONSUMO Y A TIMBRES}

La caracteristica más impresionante de la reforma de estos impuestos es la ausencia del cambio. Por lo tanto, el propósito de esta sección no es analizar los cambios, sino analizar la naturaleza de b que queda al fin del proceso de reforma.

\section{La Incidencla}

La demanda por todos los productos gravados por el impuesto al consumo es probablemente inelástica (vertical) por varias razones: Todas las bebidas alcohólicas, y lo que es tal vez su sustituto más cercano, bebidas gaseosas, son gravados por el impuesto, y, por to tanto, es dificil escapar del impuesto tratando de encontrar un sustituto que no tiene impuesto. Los derivados del petróleo son necesidades. La demanda de bienes de lujo puede ser inelástica porque los precios pueden ser una porción pequena de los ingresos altos de las personas que compran este tipo de producto. La demanda por los productos gravados por el Timbre es probablemente inelástica porque el impuesto es general, y asi los consumidores no pueden escapar al impuesto por otros bienes.

El gráfico 5 ilustra el efecto de un impuesto sobre un bien con una 
demanda inelástica. El impuesto causa un aumento vertical de la oferta que iguala el impuesto sobre cada unidad (2 colones). $O_{2}$ y $\mathrm{D}$ establecen un precio nuevo de 8 colones; el precio pagado por el consumidor sube por el monto del impuesto, mientras que el precio neto recibido por productores queda constante. Asl, el consumidor paga el impuesto. El impuesto sobre bienes de tujo es progresivo porque personas más ricas pagan estos impuestos. El impuesto sobre la venta de otros bienes es regresivo porque la proporción del presupuesto gastada en consumo cae con un aumento del ingreso. Si, por ejemplo, la tasa efectiva de Timbres es de $15 \%$, un consumidor que tiene un ingreso de 5,000 colones, y que gasta todo su ingreso para comprar bienes necesarios, paga $15 \%$ de su ingreso total en forma de impuesto. Otro consumidor que tiene un ingreso de 100,000 colones y que gana 75,000 colones, paga $15 \%$ sobre bs 75,000 y solamente $11.3 \%$ de en ingreso total en forma del impuesto.
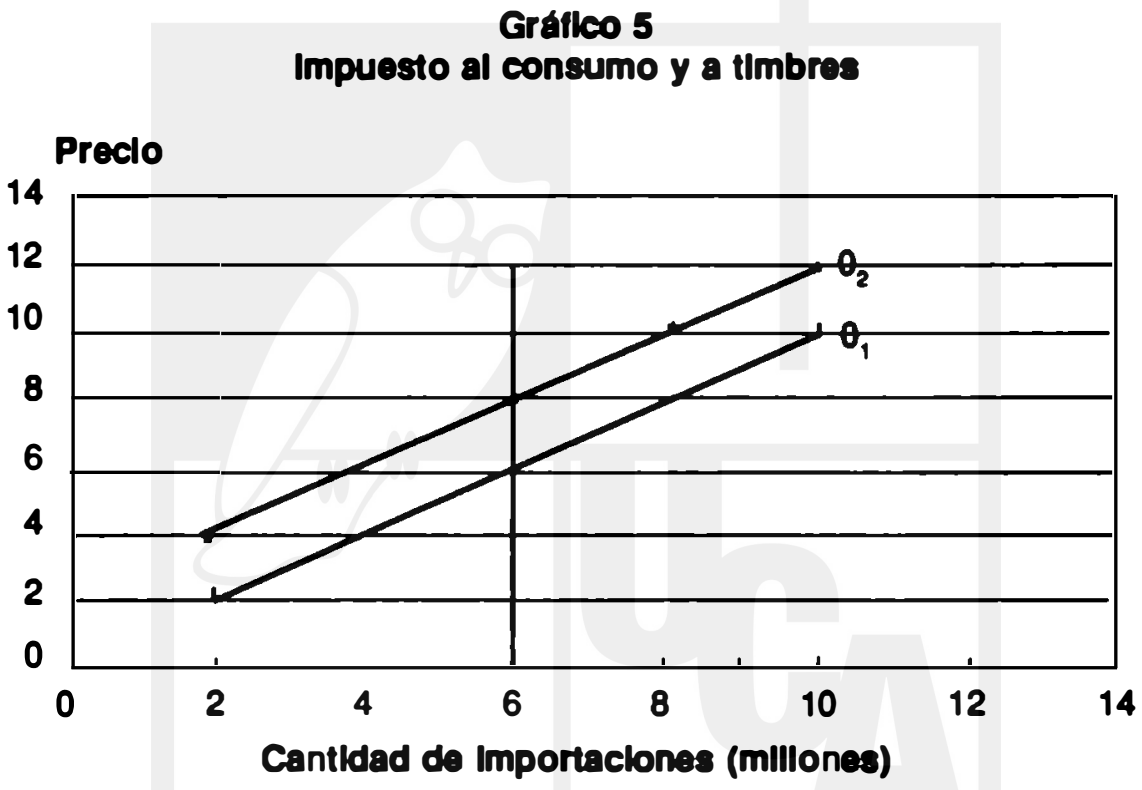

- Demanda $\longrightarrow$ Oferta $1 \quad$ Oferta 2

\section{El Impuesto sobre el Valor Agregado (IVA)}

Es bien reconocido que el impuesto sobre Timbres es un Impuesto particularmente malo. Se aplica el impuesto a todas las ventas, incluso 
las ventas entre productores. Asi el impuesto causa una discriminación arbitraria en contra de productos que tienen muchas etapas de producción. También es fácil evadir el impuesto. Por to tanto el plan del gobierno es reemplazar en 1992 el impuesto de Timbres por el Impuesto sobre el Valor Agregado (IVA). ${ }^{28}$

EI IVA es un impuesto gravado en cada etapa de producción sobre solamente el incremento del precio, en vez del precio total como en el caso de los Timbres. El precio del bien final es la sumatoria de los incrementos en precios de bienes intermedios. Por esto, el IVA es equivalente en su base a un impuesto gravado solamente sobre el precio de un bien final. El IVA elimina la distorsión de los Timbres, y es más fácil administrarlo para evitar la evasión. A pesar de estas ventajas reales, el IVA queda un impuesto sobre las ventas. Como antes, el consumidor paga el IVA, y, excepto en el caso de bienes de lujo, el impuesto es regresivo.

Los impuestos a la venta son impuestos inferiores por varias razones. Estos impuestos son regresivos, causando que la gente de menos ingresos pague una proporción relativamente grande de su ingreso para el impuesto. La incorporación de más ventas a $5 \%$ de timbres y la política administrativa de reducir la evasión del impuesto sobre la venta va a castigar a los pobres y reducir su capacidad de incorporarse en el proceso de desarrollo. Aun peor, los impuestos son gravados en una manera impersonal, y no toman en cuenta ni la capacidad de pagar ni las circunstancias personales del pagador. En los Estados Unidos, el impuesto sobre las ventas es "el elemento más regresivo de toda la estructura tributaria".23

\section{LA PARTE III: LAS IMPLICACIONES PARA EL DESARROLLO}

\section{Un resumen}

El patrón general que se ve en la reforma tributaria es una reducción grande de los impuestos progresivos y poco cambio en los impuestos regresivos. Se reduce la tasa marginal máxima del impuesto progresivo sobre la renta de $60 \%$ a $20-25 \%$; se reduce la tasa marginal máxima del impuesto progresivo sobre la renta de empresas de $35 \%$ a $20-25 \%$, se elimina el impuesto progresivo sobre el patrimonio tanto de personas como de empresas.

En general, se ve un aumento gradual de los impuestos regresivos: se elimina dos impuestos regresivos al consumo de productos pero estos daban muy poco ingreso tributario; se incorpora a tributar con el $5 \%$ 
del impuesto regresivo de Timbres sobre ventas que antes pagaban menos; se hace esfuerzos administrativos para reducir la evasión de Timbres. La excepción principal a este patrón es que se reduce el impuesto regresivo sobre las importaciones. De todo esto, se puede concluir que la primera tendencia de la reforma propuesta es reduoir bastante los ingresos tributarios del gobierno. La segunda es aumentar la regresividad del sistema.

El análisis de este trabajo da varias razones para creer que los cambios vayan a crear un déficit fiscal en el futuro. Las reducciones propuestas son grandes, causando inmediatamente una pérdida significativa de los ingresos tributarios. Los impuestos reducidos, los $\mathrm{Im}$ puestos Directos y los impuestos al comercio exterior, dieron $49 \%$ de los ingresos tributarios totales en 1989; el efecto inmediato de las reducciones fácilmente podría ser la pérdida de más que la mitad de estos ingresos.

Una manera de evitar este déficit es estimular la economía suficientemente para aumentar la base tal que se recuperen los ingresos tributarios perdidos. Este trabajo ha mostrado que parece dudoso que la reforma tributaria vaya a dar el estimulo necesario para recuperar los ingresos perdidos. Tanto la teoría económica como la experiencia de los Estados Unidos indican que la reducción del impuesto sobre la renta de personas no va a estimular significativamente los ahorros y la inversión. El impuesto sobre el patrimonio es equivalente a un impuesto sobre el ingreso de capital, y por lo tanto el mismo razonamiento concluye que el efecto de esta reducción será igualmente limitado. La reducción del impuesto sobre la renta de empresas puede estimular los ahorros, pero ¿van a invertir en El Salvador los empresarios? La destrucción de empresas locales puede compensar el estimulo a empresas salvadorenas dado por la reducción de los impuestos sobre importaciones.

Si la base tributaria no crece suficientemente y si un déficit aparece, ¿Cuál será la respuesta del gobierno? Parece dudoso que vaya a dar marcha atrás y aumente las tasas de los impuestos progresivos. Si no, el gobiemo tiene que aumentar las tasas de impuestos regresivos, o reducir los bienes y servicios públicos. Esto daría todavia otro elemento regresivo a la estructura tributaria y reduciria todavía más la oportunidad de las mayorlas para incorporarse en el proceso de desartollo.

La esperanza de evitar esto es aumentar el consumo de las personas que disfrutan un aumento de su ingreso disponible por las rebajas de los impuestos y reducir la evasión del impuesto sobre la renta. Se puede también reducir el contrabando de los importadores y reducir 
la evasión de Timbres, y de hecho esto es el plan del gobiemo, pero el costo será una estructura tributaria todavía más regresiva y una limitación todavia más grande de las oportunidades de las mayorlas para asociarse con el proceso de desarrollo.

La esperanza de evitar esto es aumentar el consumo de las personas que disfrutan un aumento de su ingreso disponible por las rebajas de los impuestos y reducir la evasión del impuesto sobre la renta. Se puede también reducir el contrabando de los importadores y reducir la evasión de Timbres, y de hecho esto es el plan del gobiemo, pero el costo será una estructura tributaria todavia más regresiva y una limitación todavia más grande de las oportunidades de las mayorias para asociarse con el proceso de desarrollo.

\section{EL PROCESO DE DESARROLLO}

Los cambios del sistema tributario implican un planteamiento para el desarrollo. Las reducciones de los impuestos progresivos implican que la estrategia tributaria es aumentar los ingresos y los ahorros de las personas más ricas del país y asi estimular la inversión. Las mayorias populares pagarán más impuestos regresivos por reducir la evasión de los impuestos regresivos o por aumentar las tasas de estos impuestos. En consecuencia, el papel de los ricos es encabezar el proceso de desarrollo. El papel de las mayorias es seguir a los ricos y tomar los empleos creados por ellos.

Esto es una forma de la estrategia de "Trickle Down" que ha sido rechazada por los economistas del desarrollo desde la década de los 70 porque los beneficios del desarrollo no llegaban a la gente más necesitada ${ }^{30}$. El desempleo perdura. La pobreza extrema perdura. La brecha entre los ricos y los pobres crece. Marques escribe "el crecimiento no alcanza automáticamente a las mayorias... Si los activos están altamente concentrados inicialmente, crecimiento y el funcionamiento automático del mercado pueden causar más concentración de activos y un aumento de la pobreza absoluta".31

\section{UNA ESTRATEGIA ALTERNATIVA}

Un planteamiento alternativo para incorporar a las mayorias en el proceso de desarrollo es el planteamiento de las "Necesidades Básicas". Este planteamiento se envolvió en un desilusionamiento al sobreenfatizar la acumulacion del capital por la civilización de los ahorros. Los partidarios de acumular capital pensaban que los gastos para programas sociales eran gastos para el consumo que, en contraste con gastos para la inversión, afectaron adversamente el desarrollo. 
En un trabajo que comenzó un avance fundamental para la teorla del desarrollo, Gary Becker arguyó que el concepto de la Inversión debe Inchir no sólo los gastos para el capital físico, sino tamblén los gastos para to que el llamó el "capital humano".32 La inversión en el capital humano incluye los gastos para proveer la nutrición, la educación, la salud, y cualesquiera otras necesidades básicas no satisfechas que son especificas a paises particulares. Se puede extender el concepto para ayudar a las micro y pequenas empresas del sector informal.

El objetivo de satisfacer las necesidades básicas es proveer las oportunidades para el pleno desarrollo físico, mental y social del individuo. Aqui, los gastos no son considerados como consumo, sino como una inversión que habilita a las mayorias a participar en el proceso de desarrollo según su potencial. En vez de retrasar el desarrollo, contribuyen al desarrollo. El satisfacer las necesidades básicas es una estrategia de desarrollo balanceado que incorpora a las mayorlas en el proceso de desarrollo y que les permite compartir el liderazgo de ese proceso según su potencial. Aqui, las mayorias hacen más que seguir el liderazgo de un segmento privilegiado de la sociedad; comparten ese liderazgo.

Las razones fundamentales a favor de satisfacer las necesidades más básicas son simples. La educación crea una fuerza de trabajo más especializada y más productiva. La salud y la nutrición reducen el ausentismo y aumentan la productividad de los trabajadores. La salud y la nutrición también mejoran la capacidad de los niños para aprender en la escuela y aumentan su productividad futura.

Un cuerpo grande de investigaciones demuestra que satisfacer las necesidades básicas de las mayorias aumenta su productividad y, por esto, su contribución al desarrollo. Para ilustrar, Norman Hicks relacionó la expectativa de vida (una manera de medir la satisfacción de necesidades básicas) con el crecimiento del ingreso para un grupo de 83 paises. Sus resultados mostraron que los 12 paises con una expectativa de vida más alta que la esperada crecieron a una tasa casi el doble de la tasa promedio de la muestra ${ }^{33}$. Esto indica que en vez de retardar el desarrollo, el satisfacer las necesidades básicas lo acelera. Se pueden citar muchos otros estudios que muestran que el satisfacer las necesidades básicas es una estrategia eficaz para el desarrollo ${ }^{34}$.

Referencias repetidas a la importancia de satisfacer las necesidades básicas por todo el plan económico de desarrollo muestran que el gobiemo salvadoreno reconoce el potencial para estimular el desarrollo al satisfacer las necesidades básicas de las mayorias. Se lee, por ejern- 
plo, que la estrategia social del gobiemo incluye "incrementar la inversión en capital humano, dando prioridad en su orden a las principales carencias sociales como son: salud y nutrición, educación... La adecuada satisfacción de estas necesidades redunda a su vez en incrementos en la producción y productividad, y por ende en el nivel de empleo $e$ ingresos,.... ${ }^{35}$ El plan sigue describiendo en detalle las necesidades básicas no satisfechas del pueblo salvadoreno y especificando las metas y los horarios para satisfacer esas necesidades.

Desgraciadamente, le falta al plan tomar el paso final y crucial de hacer un compromiso claro y fuerte para levantar los fondos que son necesarios para satisfacer las necesidades básicas del pueblo. En la sección del plan titulada "Gasto Social Para el Quinquenio 1990-1994", se lee "De acuerdo a la estrategia de desarrollo social... se ha estimado en... 3,740 millones de colones la inversión en capital humano... Los recursos destinados a inversión en capital humano serán proporcionados fundamentalmente por la Agencia Internacional para el Desarrollo (AID) y el Programa Mundial de Alimentos (PMA), los cuales se encuentran en proceso de negociación". El plan concluye con toda franqueza: "Es importante resaltar que de acuerdo a los objetivos de mediano plazo de reducir significativamente la extrema pobreza y elevar la calidad de vida de la población, los recursos antes mencionados resultan insuficientes" ${ }^{30}$

Anteriormente, el plan compromete al gobierno a "Modificar en forma gradual la estructura sectorial de la inversión en favor de proyectos y programas de carácter social, dando prioridad a la inversión en capital humano y focalizando el esfuerzo hacia los grupos en extrema pobreza". ${ }^{37}$ En otro lugar, el plan compromete al gobierno a establecer un "Fondo de Inversión Social" (FIS) cuyo papel será en parte "desarrollar funciones de captación de recursos financieros nacionales e internacionales". ${ }^{30}$ Estos pasos son positivos, pero los fondos para satisfacer las necesidades básicas quedan inseguros y es posible que nunca serán obtenidos. Los fondos quedan inseguros en parte porque el gobierno no está utilizando el sistema tributario para recaudarlos.

\section{UNA REFORMA TRIBUTARIA ALTERNATIVA}

¿Cómo se puede ajustar la reforma tributaria para asegurar los fondos necesarios para integrar a las mayorias populares más plenamente en el proceso de desarrollo? Se podría comenzar con una reorientación profunda de la reforma administrativa que deja de enfatizar tanto los impuestos regresivos y que hace esfuerzos para construir e implementar una estructura tributaria progresiva. Una manera de co- 
menzar esto serla aumentar el uso del impuesto sobre la renta de las personas y del impuesto sobre el patrimonio. El impuesto sobre la renta de las personas, el mejor de todos los impuestos, es equitativo, distorsiona poco las decisiones económicas, no reduce significativamente los ahorros y la inversión, y es factible administrarto en EI Salvador ${ }^{30}$. La concentración extrema de la renta en EI Salvador implica una concentración extrema de la capacidad para pagar; esto pide una estructura de impuestos altamente progresiva. Se podría lograr esto al cancelar las reducciones de las tasas marginales del impuesto y comenzando una campana fuerte para eliminar la evasión.

El impuesto sobre el patrimonio, como el impuesto sobre la renta personal, no reduce significativamente los ahorros y la inversión, y es factible administrarto en El Salvador. El impuesto es equitativo porque el patrimonio es una medida de la capacidad de pago que complementa la renta personal. Las consideraciones que apoyan tasas progresivas a la renta de las personas justifican tasas progresivas al patrimonio $y$, de veras, se pueden justificar tasas aun más progresivas en el caso del impuesto sobre el patrimonio. El impuesto puede hacer una contribución especialmente valiosa al objetivo de reducir la desigualdad, porque el patrimonio es más concentrado que la renta. Un impuesto progresivo sobre la tierra puede estimular el uso más intensivo de la tierra y la venta de la tierra ociosa. Se puede aumentar el uso del impuesto sobre el patrimonio cancelando la reducción de este impuesto, aumentando la progresividad del impuesto, renovando el catastro del patrimonio, y haciendo el esfuerzo necesario para eliminar la evasión.

El impuesto sobre la renta de las personas y el impuesto sobre el patrimonio deben ser la base de la estructura progresiva de los impuestos, pero se puede considerar el uso de otros impuestos también. La reducción del impuesto sobre la renta de las empresas puede ser una manera de aumentar los ahomos, aunque es posible que estos ahorros no serán invertidos en El Salvador. Hay que juzgar si el desarrollo que viene de aumentar los ahorros de las empresas es más grande y más importante que el desarrollo que vendria de tributar las empresas y utilizar los fondos para liberar el potencial productivo del pueblo. También, se puede considerar el mantener o el aumentar la progresividad de este impuesto para promover las pequenas empresas.

Por otra parte, se puede luchar para reducir el uso del impuesto regresivo de Timbres. Si se tiene éxito en hacer el sistema más progresivo, se puede reducir la tasa del impuesto sobre las ventas, sea el Timbre o el IVA. Esto promovería el desarrollo por lo menos de dos 
maneras. Marques escribe que 'Un cuerpo grande de investigaciones han dernostrado que los campesinos pueden ahorrar de sus ingresos tanto como las personas de los ingresos más allos"..0 Segundo, las reducciones de los impuestos sobre las ventas darian al pueblo más dinero para satisfacer sus necesidades básicas. Aun después de que el gobierno construya escuelas, por ejemplo, las mayorlas necesitan dinero para pagar los costos privados de educación, incluyendo los costos de la ropa, de los materiales educativos, y el costo de oportunidad de tener a los niños estudiando en el sabón de clase en vez de trabajando en el campo.

Esta reforma no estarla libre de dificultades. Si es factible aumentar el uso del impuesto sobre la renta y sobre el patrimonio, pero es menos factible que aumentar el uso del IVA."1 Los gobiemos anteriores, por ejemplo, construyeron un catastro de inmuebles del patrimonio del pais, pero no lo han mantenido durante la década de la guerra civil, y es costoso renovarlo y mantenerlo. EI IVA, por contraste, tiene características que permite al gobierno reducir evasión fácilmente. EI gobierno quiere los fondos "ahorita", y la manera más fácil de obtenerlos es utilizar los impuestos regresivos como el IVA.

Las dificultades de hacer la estructura tributaria más beneficiosa nos recuerdan que el desarrollo verdadero - "el desarrollo de toda la persona y de todas las personas" - exige un compromiso especiar². Exige la "solidaridad" del Papa Juan Pablo II que "no es, pues, un sentimiento superficial por los males de tantas personas, cercanas 0 lejanas. Al contrario, es la determinación firme y perseverante de empenarse por el bien común; es ceder, por el bien de todos y cada uno, para que todos seamos verdaderamente responsables de todos" ${ }^{n}{ }^{43}$ Cuesta, pero se puede hacerlo. De veras, se quiere hacerlo porque asi y solo asl se logrará el objetivo digno del Plan Económico, "romper el circulo vicioso de la pobreza para crear el círculo virtuoso del progreso económico y social". 44 


\section{APENDICE I}

\section{ESTRUCTURA TRIBUTARIA DE EL SALVADOR}

I. IMPUESTOS DIRECTOS $(30.9 \%, 1989)$

A. IMPUESTOS SOBRE LA RENTA $(23.7 \%, 1989)$

1. IMPUESTO SOBRE LA RENTA DE LAS PERSONAS $(10.3 \%, 1989)$

Impuesto que grava los ingresos obtenidos en el pais, por las personas naturales nacionales 0 extranjeras.

2. IMPUESTO SOBRE LA RENTA DE LAS EMPRESAS

(13.4\%, 1989)

Impuesto sobre las rentas que obtenga toda empresa nacional o extranjera domiciliada en el pais.

B. IMPUESTO SOBRE EL PATRIMONIO $(4.8 \%, 1989)$

1. IMPUESTO SOBRE EL PATRIMONIO DE LAS PERSONAS $(1.6 \%, 1989)$

Impuesto sobre el patrimonio que posean en el territorio salvadoreno, las personas naturales nacionales y extranjeras.

2. IMPUESTO SOBRE EL PATRIMONIO DE LAS EMPRESAS (3.2\%, 1989)

Impuesto sobre el patrimonio que posean en EI Salvador, las personas juridicas nacionales y extranjeras.

C. IMPUESTO SOBRE LAS TRANSFERENCIAS DE LAS PROPIEDADES $(2.4 \%, 1989)$

1. a Título Oneroso $(1.7 \%, 1989)$

Impuesto sobre las transferencias de derecho sobre bienes raices entre personas, salvo las excepciones.

2. a Título Gratuito $(0.2 \%, 1989)$

Impuesto sobre los bienes muebles e inmuebles donados 0 dados en fideicomiso

3. por Causa de Muerte $(0.5 \%, 1989)$

Impuesto por la transmisión de derechos de bienes por herencia y legados por causa de muerte. 
II. IMPUESTOS INDIRECTOS $(69.1 \%, 1989)$

A. IMPUESTOS AL COMERCIO EXTERIOR (18.1\%, 1989)

1. IMPUESTO SOBRE LA IMPORTACION (12.7\%, 1989)

Derechos que se imponen sobre las mercaderlas importadas.

2. IMPUESTOS SOBRE LA EXPORTACION $(5.4 \%, 1989)$

Derechos que se impongan sobre la exportación de mercaderlas y productos.

Café (5.1\%) Camarón (0.2\%), Azúcar (0.1\%), Mercaderlas no clasificadas $(.003 \%)$.

B. IMPUESTOS SOBRE EL CONSUMO DE PRODUCTOS

(17.\%, 1989)

Impuestos sobre el consumo interno de productos, ya sean de producción nacional o importados.

Cerveza, Alcoholes, Productos de Tabaco, Azúcar, Gaseosas, Fósforos y Cerillos, Selectivo (consumo suntuario), etc.

A. IMPUESTO SOBRE EL USO DE SERVICIOS $(1.7 \%, 1989)$ Impuesto sobre uso de servicios.

Pasajes Aéreos y Maritimos, Espectáculos públicos, Matrícula de vehículos, uso de servicios no clasificados.

B. IMPUESTO SOBRE ACTIVIDADES PRODUCTIVAS Y COMERCIALES $(0.3 \%, 1989)$

Ingresos por licencias y permisos para ejercer actividades de producción y comercialización de bienes y servicios.

C. IMPUESTO SOBRE ACTOS JURIDICOS Y TRANSACCIONES $(31.5 \%, 1989)$

1. IMPUESTO DE PAPEL SELLADO $(0.4 \%, 1989)$

Impuesto sobre actos, contratos y obligaciones que establece la ley mediante el uso de la especie fiscal denominada "Papel Selladon.

2. IMPUESTO DE TIMBRES $(31.1 \%, 1989)$

Impuesto (sobre ventas) mediante el uso de la especie denominada "Timbres Fiscales" y en cualquier documento que ampare la venta de mercaderlas y servicios. 


\section{APENDICE ॥}

\section{CAMBIOS REALIZADOS Y PROPUESTOS \\ DE LA ESTRUCTURA TRIBUTARIA DE EL SALVADOR}

I. CAMBIOS DE IMPUESTOS DIRECTOS $\mathbf{3 0 . 9 \%}$ de ingresos tributarios 1989)

A. SOBRE LA RENTA DE PERSONAS (10.3\%, 1989)

1. Realizados:

a. La tasa marginal máxima ha sido reducida de $60 \%$ a $50 \%$.

b. El número de tramos ha sido reducido de 24 a 7 .

c. La exención de renta imponible ha sido levantado de 12,000 a 18,000 colones.

2. Propuestos:

a. Reducir la tasa marginal máxima a 20-25\%.

B. SOBRE LA RENTA DE EMPRESAS $(13.4 \%, 1989)$

1. Realizados:

a. La máxima tasa marginal ha sido reducida de $35 \%$ a $30 \%$

b. El número de tramas ha sido reducido de 5 a 3.

2. Propuestos:

a. Reducir la tasa marginal máxima a $20-25 \%$.

b. Eliminar tramos para tener una tasa única.

C. IMPUESTO AL PATRIMONIO $(4.8 \%, 1989)$

1. Realizados:

a. Se establece dos tablas para calcular el impuesto sobre el patrimonio, una para las personas naturales, y otra para las jurídicas, en sustitución de la tabla única que existia.

b. Piso elevado

1. el patrimonio mínimo imponible para las personas naturales, será elevado de 150,000 colones a 300,000 colones;

2. el patrimonio mínimo imponible para las personas jurídicas será elevado de 150,000 colones a 500,000 colones. 
c. Número de tramos reducidos:

1. para personas naturales, de 6 a 4.

2. para personas jurídicas, de 6 a 3.

d. Tasas reducidas

1. Tasa marginal máxima es reducida de $2.5 \%$ a $2 \%$.

2. Propuestos:

a. Eliminación completa en 1992.

II. CAMBIOS DE IMPUESTOS INDIRECTOS (69.2\%, 1989).

A. IMPUESTOS AL COMERCIO EXTERIOR $(18.1 \%, 1989)$

1. IMPUESTOS A LA IMPORTACION (12.7\%, 1989).

a. Realizados:

1. Simplificación de 25 tarifas a 7 tarifas.

2. Tarifas oscilan entre el $5 \%$ y $50 \%$; anteriomente, oscilaban en el $1 \%$ y $29 \%$.

b. Propuestos:

1. Un arancel uniforme entre el $15 \%$ y el $25 \%$.

2. IMPUESTO A LAS EXPORTACIONES $(5.4 \%, 1989)$

a. Realizados:

1. Eliminación del impuesto a la exportación de azúcar y de camarón.

2. Nueva tabla de cálculo del impuesto por quintal de café oro de $\mathbf{4 6} \mathrm{kgs}$ ha sido sustituida por la siguiente:

a. Precio hasta $\$ 45$ (FOB puerto salvadoreno exento.

b. Precio de $\$ 45.01$ y más, 30\% sobre el excedente de $\$ 45$.

b. Propuesto:

1. Eliminación del impuesto sobre la exportación de café.

B. IMPUESTO AL CONSUMO DE PRODUCTOS (17.5\%, 1989)

1. Realizados:

a. Ley del impuesto sobre el azúcar (1961) es derogada.

b. Ley del impuesto sobre los fósforos (1959) es derogada. 
C. IMPUESTOS AL USO DE SERVICIOS (1.7\%, 1989)

2. Realizados:

a. Ley de impuesto sobre espectáculos públicos derogada.

D. GRAVAMENES E IMPUESTOS SOBRE ACTIVIDADES PRODUCTIVAS Y COMERCIALES $(0.3 \%, 1989)$.

1. Realizados:

a. Impuesto sobre producción, distribución, o arrendamiento de peliculas eliminado.

b. Impuesto sobre establecimientos de Compra Venta de Objetos Usados (1942) eliminado.

E. IMPUESTO SOBRE ACTOS JURIDICOS Y TRANSACCIONES (31.5\%, 1989)

1. IMPUESTO DE TIMBRES FISCALES $(31.1 \%, 1989)$

a. Realizados:

1. Se incorpora a tributar con el $5 \%$ de Timbres:

a. Venta de mercaderias o prestación de servicios, que presten comerciantes o personas naturales y juridicas de cualquier naturaleza, siempre que su activo sea de 20,000 colones o más y ventas 0 ingresos anuales de 50,000 colones o más.

b. Etc.

b. Propuestos

1. Cambiar al Impuesto Valor Agregado (IVA) 1992. 


\section{REFERENCIAS}

\section{Llbros}

Aaron, Henry J. Who Pays the Property Tax?. Washington, D.C.: The Brookings Institution (1975).

Goode, Richard. Govemment Finance in Developing Countries. Washington, D.C: The Brookings Institution (1984).

Hidalgo, Amado Gavidia. Estudio de las Finanzas Públicas de El Salvador. EI Salvador: Editorial AHORA (1989).

Juan Pablo II. Carta Enciclica Sollicitudo Rei Socialis. Santa Ana, El Salvador: Instituto de Promoción Humana, Universidad Católica de Occidente (1987).

Lazo M., José Francisco. La Estructura Tributaria de EI Salvador. CINAS, agosto (1987).

Musgrave, Richard A. y Musgrave, Peggy B. Public Finance in Theory and Practice, 5th ed. New York: McGraw-Hill Book Company (1989).

\section{Monograflas}

Fundación Salvadoreña para el Desarrollo Económico y Social (FUSADES). Anáisis Crítico de la Politica Fiscal. San Salvador (diciembre, 1986).

- B. Bases para un Nuevo Modelo Tributario, San Salvador (1987).

- La Necesidad de un Nuevo Modelo Económico para EI Salvador: Lineamientos Generales de una Estrategia. San Salvador (1985).

Harberger, Arnold C. and Wisecarver, Daniel L. Guidelines for Development: Suggestions for Economic Policy in El Salvador. San Salvador: Fundación Salvadoreña para el Desarrollo Económico y Social (FUSADES), Documento de Trabajo № 12 (abril 1990).

Marques, José. Towards a Strategy to Address the Basic Needs of the Poor in

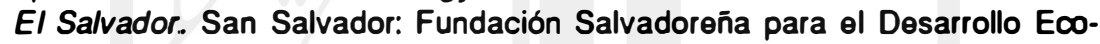
nómico y Social (FUSADES), Documento de Trabajo № 11 (1990).

Ministerio de Hacienda. Manual de Clasificación de Ingresos. El Salvador (1987).

Ministerio de Planificación. Plan de Desarrollo Económico y Social 1989-1994. El Salvador (1990).

Peat Marwick. Las Reformas Tributarias en El Salvador y su Incidencia EI Salvador (1990).

\section{Articulos/Informes}

De Wulf, Luc. "Fiscal Incidence Studies in Developing Countries: Survey and Critique". IMF Staff Papors, Vol. 22 (March, 1975).

Instituto de Investigaciones Económicas de la Facultad de Ciencias Económicas de la Universidad de El Salvador. "Sobre la Economía (Social) de Mercado: 
las Medidas Económicas del actual Gobierno", Coyuntura Económica: Boletln Informativo y Análisis Económico, Ano N, No 27 (SeptiembreDiciembre, 1989), pp. 2-9.

Marsden, Kieth. "Links between Taxes and Economic Growh: Some Empirical Evidenco". World Bank Staff Working Papers. № 605 (1983).

Ministerio de Hacienda. "Algunas consideraciones sobre la Reforma Tributaria en El Salvador". San Salvador, (enero, 1990).

. "Ley de Presupuesto 1990", Diario Oricial (el 22 de diciembre de 1989). - "Recientes Reformas Tributarias vigentes a patir del 1 de enero de 1990". San Salvador, (enero, 1990).

McGuire, J. Michael. "La Micro y Pequeña Empresa: Instrumento Efectivo de Desarrollo de Empleo", Administración y Empresa, № 44 (abril-junio, 1990), pp. 53-64.

Pechman, Joseph A. "The Future of the Income Tax", American Economic Roviow (march, 1990), Pp. 1-20.

Ruano, Evelio. "Evaluación Preliminar del Programa de Reforma Tributaria", Coyuntura Económica: Boletin Informativo y Análisis Económico, Año II, № 10 (enero de 1987), pp. 8-27.

Tanzi, Vito, "Personal Income Taxation in Latin America: Obstacles and Possibilities", National Tax Joumal, Vol 19 (June 1966), pp. 156-62.

\section{Entrovlstas}

Lic. Rogelio Tovar, Director de Impuestos Internos, Ministerio de Hacienda, San Salvador (29 de agosto de 1990). , (29 de enero de 1991).

\section{NOTAS FINALES}

1. Juan Pablo II, Sollicitudo Roi Socialis, Santa Ana, El Salvador: Instituto de Promoción Humana, Universidad Católica de Occidente (1987), p. 57.

2. Bid., Pp. 14, 25-26.

3. Ibid., pp. 7, 56.

4. La fuente principal del resumen es: Ministerio de Hacienda, Manual de Clasificación de Ingresos (1987), pp. 1-25.

5. Ministerio de Hacienda, Algunas Consideraciones sobre la Reforma Tributaria en El Salvador (24 de enero de 1990), p. 13.

6. Ministerio de Hacienda, Recientes Reformas Tributarias Vigentes a patir del 1 de enero de 1990 (enero de 1990). Peat Marwick, Las Reformas Tributarias on El Salvador y su Incidencia, San Salvador (1990). Ministerio de Hacienda, algunas consideraciones, op. cit Entrevistas con el Lic. Rogelio Tovar, Director de Impuestos Internos, Ministerio de Hacienda el 29 de agosto de 1990 y el 29 de enero de 1991.

7. Richard A. Musgrave y Peggy B. Musgrave, Public Finance in Theory and 
Practice, 5 th od., New York: McGrae-Hill Book Company (1989), p. 242. En el largo lazo, esta conclusión puede ser parcialmente compensada por un movimiento del trabajo y del capital para palses extranjeros. Un impuesto sobre el ingreso del capital puede inducir a los residentes a invertir el extranjero. Algunas personas profesionales y trabajadores diestros están listos a emigrar a palses en donde se puede ganar más. La emigración del capital y del trabajo es limitada por factores como el conocimiento imperfecto, los impuestos de otros paises, y los muchos impedimentos psicológicos y legales.

8. Los impuestos son expresados como un porcentaje de renta imponible menos una exención. Por ejemplo, el impuesto sobre una renta imponible de 45,000 colones es "20\% de la renta imponible menos 3,900 colones".

9. Richard Goode, Government Finance in Developing Countries, Washington, D.C.: The Brookings Institution (1984), p. 104.

10. Ministerio de Hacienda. Algunas Consideraciones, op. cit., p. 9.

11. Goode, op cit.p. 245.

12. Musgrave, op. cit., p. 304.

13. Goode, op. cit., p. 143.

14. Musgrave, op. cit., pp. 303-304.

15. Joseph A. Pechman, "The Future of the Income Tax", American Economic Review (March 1990), p. 7.

16. Entrevista con el Director de Impuestos Internos, op. cit., (el 29 de agosto de 1990).

17. El único caso en que se puede aumentar utilidades por trasladar un impuesto sobre la renta de la empresa adelante a consumidores es el caso en que la empresa no maximizaba utilidades antes del impuesto. $\mathrm{Si}$, por ejemplo, la empresa estaba maximizando ventas en vez de utilidades antes del impuesto, el impuesto puede causar un aumento de precio y un movimiento hacia la posición que maximiza utilidades. En esta manera, una parte del impuesto puede ser trasladado adelante a consumidores. Musgrave, op. cit., p. 265.

18. En el largo plazo, un impuesto sobre la renta de las empresas podrla causar algún movimiento de capital a países extranjeros. Sin embargo, este movimiento es probablemente bien limitado por dos razones: (1) solamente el exceso del impuesto doméstico sobre el impuesto en el extranjero afectará un flujo de capital; (2) la igualación de tasas de utilidades después de impuestos es incompleta. Goode, op. cit., p. 113115.

19. Musgrave, op. cit., p. 305.

20. El estudio de Birch está resumido en J. Michael McGuire, "La Micro y Pequeña Empresa: Instrumento Efectivo de Desarrollo de Empleo", Administración y Empresa, Número 44 (abril-junio 1990), pp. 53-58.

21. Ministerio de Hacienda, Algunas Consideraciones, op. cit., p. 13.

22. Henry J. Aaron, Who Pays the Prosperty Tax: a New York View, Washington, D.C.: The Brookings Institution (1975), Chapter 3. 
23. Asumir que el valor del patrimonio es 100 colones. Un retorno de $10 \%$ del valor de 10 colones. Un impuesto de 5 colones iguala $5 \%$ del valor del patrimonio (5 colones/100 colones - .05) y $50 \%$ del retorno (5 colones/10 colones - 50).

24. Ibid., pp. 50-51.

25. Entrevista con el Director de Impuestos Internos, op. cit., un catastro del patrimonio existe, pero no ha sido renovado desde 1980 cuando la guerra civil comenzó.

26. Goode, op. cit., pp. 175-77. Se define elasticidad precio ser (cambio porcentual de producción) / (cambio porcentual de precio).

27. Entrevista con el Director de Impuestos Internos, op. cit., (el 29 de enero de 1991).

28. Entrevista con el Director de Impuestos Internos, op. cit.,(29 de enero de 1991).

29. Musgrave, op. cit., p. 404.

30. Goode, op. cit., Chapter 10. Marques, op. cit., pp. 6-7.

31. Marques, op. cit., p. 17.

32. Gary Becker, Human Capital, Now York: Columbia University Press (1964). Citado en José Marques, Towards a Strategy to Address the Basic Needs of the Poor in El Salvador, San Salvador: Fundacion Salvadoreña para El Desarrollo Económico y Social (FUSADES), Documento de Trabajo No 11 (1990), p. 5.

33. Norman Hicks, "Is There a Trade-off Between Growth and Basic Needs?", Development and Finance, (June 1980). Citado en Marques, op. cit., p. 9.

34. Marques cita un número de estudios. Op. cit., Chapter 2.

35. Ministerio de Planificación, Plan de Desarrollo Económico y Social 19891994, El Salvador (1990), p. 56.

36. Ibid., pp. 79-80.

37. Ibid., p. 45.

38. Ibid., p. 62.

39. Entrevista, Director de Impuestos Internos, op. cit. (el 29 de enero de 1991).

40. Marques, op. cit., p. 7.

41. Entrevista con el Director de Impuestos Internos, op. cit., (el 29 de enero de 1991).

42. Juan Pablo II, op. cit., p. 56.

43. Ibid., p. 74.

44. Plan Económico, op. cit., p. 1. 